\title{
ESTATUTO DA METRÓPOLE: REFLEXÕES ACERCA DO INSTITUTO LEGAL E DA GOVERNANÇA METROPOLITANA.
}

\author{
METROPOLITAN STATUTE: CONSIDERATIONS ABOUT THE LEGAL \\ INSTITUTE AND THE METROPOLITAN GOVERNANCE.
}

${ }^{1}$ Natália Sales de Oliveira

\begin{abstract}
RESUMO
O presente artigo analisa o Estatuto da Metrópole frente os maiores problemas de gestão metropolitana das principais regiões metropolitanas do país. Esta pesquisa investigou tais regiões e analisou suas forças institucional e articulações de governança; essas análises foram comparadas a um modelo paradigma considerado ideal. A partir dos resultados obtidos e do modelo ideal, foram analisadas as principais inovações trazidas pelo Estatuto e como estas se aproximam ou não dos itens considerados essenciais para uma sólida governança. Concluiu- se que a lei traz instrumentos necessários, como a gestão plena, porém não abarcou pontos essenciais como a gestão exclusiva de Funções Públicas de Interesse Comum e a instituição de Fundos de grande capacidade.
\end{abstract}

Palavras-chave: Estatuto da metrópole, Governança metropolitana, Funções públicas de interesse comum

\begin{abstract}
This paper analyzes the Estatuto da Metrópole in regards to the major metropolitan management problems about the main metropolitan regions in the country. This research investigated them and did analyzed the institutional strength and governance articulations; those analyzes where compared to an ideal model. Starting from the results and the ideal model we analyzed the main innovations brought about by the statute and how these come close to the items considered essential to a solid governance. We conclude that the Statute brings necessary instruments, like the whole management, however it has not encompassed essential points like the exclusive management of Public Functions of Common Interest and the institution of Funds of great capacity.
\end{abstract}

Keywords: estatuto da metrópole, Metropolitan governance, Public functions of common interest

\footnotetext{
${ }^{1}$ Mestre em Direito pela Universidade do Estado do Rio de Janeiro - UERJ, Rio de Janeiro (Brasil). E-mail: nataliasoliveira32@gmail.com
} 


\section{Introdução}

Este estudo foi realizado logo após a sanção e promulgação do Estatuto da Metrópole, lei 13.089/15, a qual marca um grande avanço jurídico sobre a questão metropolitana no Brasil.

Embora a Constituição Federal de 1988 já reconhecesse as regiões metropolitanas, aglomerações urbanas e microrregiões, uma lei federal que objetiva regular a governança e gestão dessas tipologias urbanas representa a constatação dessa realidade complexa. Afinal, a questão metropolitana é um fato mundial que se fortalece com a globalização; a íntima conexão entre as cidades vizinhas e a grande mobilidade de serviços, capital e pessoas entre elas é uma característica de um mundo globalizado e intrinsecamente conectado: trabalhar em uma cidade, fazer compras em outra e dormir em numa terceira, tudo em um único dia, é uma realidade comum para muitos brasileiros e outros cidadãos de regiões metropolitanas no globo.

Este estudo, portanto, originou-se com o propósito de responder em que medida o marco legal auxiliará na gestão das regiões metropolitanas do país e quais foram os avanços e eventuais pontos problemáticos - trazidos por esta lei federal sobre este aspecto. Com o objetivo de responder a esta questão, considerou-se importante passar por duas análises indispensáveis: qual o estado geral da gestão e governança das principais regiões metropolitanas do país (ou seja, como elas têm sido geridas, quais os obstáculos nessa gestão, o histórico dessas regiões e como este assunto foi abordado até então) e quais as inovações normativas trazidas pelo Estatuto com o objetivo de tratar dessa situação.

A primeira investigação foi desenvolvida através da análise das pesquisas do Instituto de Pesquisas Econômicas Aplicadas (IPEA) sobre gestão metropolitana (projeto de pesquisa denominado Governança Metropolitana no Brasil desenvolvido em 2013) que se incumbiu de estudar as regiões metropolitanas do país, suas características, tempo de existência e principais dificuldades de cada uma delas, como será detalhado a seguir. Em razão da extensão, profundidade e do caráter recente destas pesquisas, suas análises e conclusões foram utilizadas como ponto de partida para alcançar o objetivo geral deste artigo. Já a segunda investigação foi realizada através da análise da lei federal e de literatura sobre o tema.

Este artigo, portanto, está dividido em quatro seções, além desta introdução e da conclusão. Na primeira, relata-se sobre o fenômeno metropolitano e seu histórico no país; na segunda, apresenta-se as principais análises e conclusões sobre o estado geral das regiões 
metropolitanas no Brasil; na terceira, apresenta-se os principais pontos trazidos pelo Estatuto. Por fim, antes de concluir, analisa-se este marco legal e o estado geral das regiões metropolitanas, apontando as principais constatações através de uma análise comparativa.

\section{A questão metropolitana}

"A real cidade é toda a área metropolitana", escreve Briffault ao citar David Rusk (BRIFFAULT, 1999, p.4). Essa máxima estranhamente verdadeira passou a ser aceita e percebida por cidadãos e pelo próprio poder público, principalmente nas grandes cidades; é estranha porque estimula-se a desconstruir um conceito estagnado de cidade e a lidar com a realidade globalizada e metropolitana: uma pessoa pode, como ocorre frequentemente, trabalhar em uma localidade, fazer compras em uma segunda e morar em uma terceira; a educação, a cultura e até mesmo os recursos naturais acabam por servir e afetar toda uma região e não tão somente uma localidade. O conceito de cidades com domínios administrativos claramente definidos, assim como os limites territoriais de abrangência dos serviços públicos e, ainda, a tradicional separação cultural, econômica e identitária de cada uma delas não são mais tão nitidamente visíveis. Há não só o desejo, mas a necessidade da compreensão e do pensamento regional em contraposição a políticas públicas puramente locais.

Com o objetivo de confrontar o pensamento metropolitano com o localista, BRIFFAULT (1999) expõe os motivos pelos quais o primeiro interessa e é necessário. Para isso, aborda um fenômeno cotidiano nas cidades: o crescimento horizontal. À medida que elas se tornam mais dinâmicas, recebem maior contingente populacional e crescem economicamente, a dispersão de baixa intensidade se alia ao uso extensivo do território, ou seja, a cidade cresce para além de seu núcleo e suas margens passam a ser ocupadas. Esta ocupação das periferias quando não planejada, pode acarretar sérios reflexos como degradação ambiental (em função de se eliminar áreas verdes para moradia, comércios e atividades industriais), aumento de problemas urbanos como os de mobilidade em razão das distâncias para se locomover e, ainda, a crescente necessidade de ampliar a infraestrutura básica para mais partes da cidade. A questão é que os governos locais contribuem para essa dispersão através de seu poder normativo e administrativo sobre a cidade; a regulação local pode ser usada para não regrar o mercado imobiliário e contribuir com o aumento do preço da terra, expulsando para a periferia aqueles que não podem pagar por aquele preço ou, ainda, para realocar atividades industriais ou comerciais indesejadas para essas áreas (por questões econômicas, ambientais, etc.). Isso afeta toda a região quando as localidades vizinhas adotam 
o mesmo tipo de regulação e suas áreas periféricas começam a se encontrar fisicamente ou a se articular entre si econômica e/ou socialmente.

Em um contexto brasileiro, o crescimento disperso das cidades está aliado à inexistência de políticas públicas de moradia adequada, falta de regulação do mercado imobiliário e leis de zoneamento que determinam uma localidade apartada e, às vezes, distante de atividades industriais em função das peculiaridades destas. A pouca ou inexistente regulação do mercado imobiliário permite que os agentes imobiliários estabeleçam preços diferenciados por metro quadrado nas áreas da cidade em função das condições do meio ambiente, se natural ou construído; posição da zona da cidade e sua conexão com transporte público; urbanização do entorno (infraestrutura urbanística como iluminação, saneamento, acesso à água canalizada, asfalto nas ruas, etc.); acesso a centros de emprego, consumo, cultura, etc. Os preços estão vinculados à localização de determinada terra urbana e a benesses urbanísticas de que ela dispõe; quando se tem uma localização com maior infraestrutura e melhorias urbanas, o preço da terra tende a ser mais elevado; o pensamento contrário também se aplica. Isto aliado à inexistência ou poucas políticas públicas de moradia adequada, que possibilitem que pessoas de menor poder aquisitivo residam nessas áreas, impulsiona o afastamento dos núcleos em direção às margens da cidade (periferias), onde o preço da terra é menor. Ademais, um fenômeno similar à suburbanização americana também auxilia na dispersão horizontal, o crescente desejo de cidadãos com alto poder aquisitivo de residir em uma localidade isolada, com grande área verde e com poderes de construção mais flexíveis uma espécie de nova interpretação de cidades jardins - também é uma realidade a ser mencionada.

No caso de atividades industriais, em razão de necessitarem, por vezes, de maior espaço para produção ou em função de questões ambientais e de saúde ou ainda simplesmente por não se tratarem de atividades desejadas nos núcleos da cidade, ficam localizadas também em periferias, às vezes por determinação legal, auxiliando na dispersão horizontal da cidade. Esta dispersão, como bem atenta BRIFFAULT (1999), é reforçada por tecnologias de transporte e comunicação; a distância é diminuída com estas tecnologias. Essa dispersão horizontal é ainda mais intensa em cidades maiores, em que há grande contingente de pessoas e elevados preços da terra em áreas bem localizadas.

As periferias de cidades diferentes se aproximam à medida que estes fatores se concretizam. Paulatinamente, cidades distintas passam a se aproximar ao ponto de não mais poderem ser separadas física, social e/ou economicamente: não se sabe onde começa uma e 
termina a outra. Em casos como este o localismo - que preza a administração de uma cidade isolada - pode, e provavelmente o fará, falhar no atendimento a essas pessoas que vivem nestas áreas. As cidades que se conectam precisam agir de modo a prover serviços públicos também nos pontos de interceção, caso contrário, o abastecimento de água, a retirada de lixo, dentre outros serviços podem ser comprometidos.

Vinculada a esta dispersão, está a concentração de pobreza em áreas periféricas. As margens da cidade são os locais menos atraentes para investimentos, o Estado leva infraestrutura para o núcleo metropolitano por ser a área que mais atrai investimentos do setor privado e onde tem maior circulação de capital em função de concentração de determinadas atividades comerciais e turísticas; as áreas periféricas, neste caso, acabam por concentrar a população mais pobre e as atividades indesejadas pelo núcleo urbano. Para reforçar o processo de dispersão, as pessoas que residem nestes locais mais pobres, ao adquirirem uma melhoria financeira saem dessas áreas, mas como não podem arcar com os preços dos núcleos metropolitanos, vão para margens menos pobres, porém ainda em área mais periférica.

Por fim, o autor reforça a importância de se conceber a administração metropolitana em razão da existência de uma economia global. Essa abordagem se apresenta como mais adequada por permitir maior competitividade. A maior mobilidade do capital permitiu que investimentos, até mesmo os estrangeiros, chegassem em várias áreas do mundo; as localidades passaram a ter de se mostrar atraentes a este capital, ao turismo, aos homens de negócios para alcançar mais investimentos. Logo, para uma região ser mais atraente, e assim, mais competitiva, uma área metropolitana deve lidar com seus problemas econômicos e sociais, eliminando-os ou diminuindo-os consideravelmente.

Nessa esteira, o autor demonstra que decisões locais em um contexto metropolitano estão fadadas a ser ineficientes e a não solucionar as desigualdades socioeconômicas no amplo território, mas somente em pontos localizados. O localismo é um tipo de gestão que olvida os serviços de interesse comum da região, pois não possui os instrumentos necessários para gerir as funções públicas que são de interesse de toda uma área metropolitana. A gestão de águas em uma cidade pode comprometer a nascente do rio em outra, por exemplo; logo, caso não haja uma integração entre ambas as administrações a população regional poderá ser inteiramente comprometida. Os interesses das pessoas de uma cidade estão ligados aos dos seus vizinhos. Conceber o espaço metropolitano e geri-lo como tal é o caminho para se obter uma região melhor integrada e coordenada, possibilitando um desenvolvimento sustentável nos aspectos sociais, econômicos e ambientais. 
A partir dessa visão, nota-se que a consciência para o fato metropolitano é uma realidade. No Brasil, começou a ser moldado a partir do fenômeno de conurbação que faz com que os limites físicos de cidades se tornassem menos visíveis; há, portanto, a formação de uma aglomeração urbana com grande área urbanizada formada pela cidade núcleo e pelas cidades adjacentes. Quando as cidades que formam esse aglomerado possuem alto grau de integração entre si, em termos econômicos, políticos e sociais tem-se o fenômeno metropolitano em ação. Esta realidade, já há muito existente, forçou uma inovação legislativa e institucional no Brasil com a criação da Lei Complementar 14/1973 - obediente à Constituição de 1967 que instituiu a região metropolitana. Criadas pela União, inicialmente foram instituídas nove regiões, quais sejam São Paulo, Belo Horizonte, Porto Alegre, Curitiba, Salvador, Fortaleza, Recife, Belém e Rio de Janeiro, esta última em 1974.

Sob o crivo do governo militar, a intenção era estabelecer uma integração do território brasileiro forjada numa intensa interrelação entre essas unidades políticas e alicerçada numa sociedade com grande tendência de se concentrar nos grandes centros urbanos. Este modelo inicial de conduzir o fato metropolitano era formado por uma administração altamente centralizada e com pouco poder decisório para as bases locais.

Com a Constituição Federal de 1988, uma nova dimensão no nosso federalismo de integração surgiu: as regiões metropolitanas, aglomerações urbanas e microrregiões passam a ter um estatuto jurídico-constitucional diferente do anterior. O texto constitucional delegou aos governos estaduais a incumbência de criação de novas regiões metropolitanas e, portanto, estabeleceu uma visão de necessária cooperação e coordenação intergovernamental entre Estados e Municípios para que uma real gestão do fenômeno metropolitano fosse possível.

A partir de então, um significativo aumento quantitativo de regiões metropolitanas ocorreu; uma criação que, na maioria das vezes, não obedecia a critérios claros, objetivos e consistentes, tanto na sua institucionalização, quanto na definição dos municípios que as compunham. Nota-se, neste momento, um modelo de gestão que não é mais centralizado e recursos que não são tão vultosos.

Em razão do aumento do número de regiões com governanças não muito bem definidas, fraca integração entre os municípios e poucos recursos financeiros para elas, apontouse como urgente um direcionamento legal para as regiões metropolitanas. Um instrumento normativo capaz de estabelecer critérios mais objetivos para a instituição das regiões metropolitanas, de direcionar o modelo de governança e de apontar os recursos 
financeiros foi visto como essencial para que a região alcançasse seu real objetivo: melhorar a qualidade de vida de todas as pessoas que nela vivem.

Em razão disso, a sanção do Estatuto da Metrópole em janeiro deste ano (2015) foi um grande avanço normativo. Aprender a gerir e lidar com a integração econômica, política e cultural dentro da região metropolitana foi apontado como o principal objetivo.

\section{A questão metropolitana no Brasil: 40 anos de região metropolitana.}

Em 2013, o projeto de pesquisa Governança Metropolitana no Brasil realizado no âmbito da Plataforma Ipea de Pesquisa em Rede (Rede Ipea), estabeleceu, como um de seus objetivos, a análise da gestão e da governança metropolitanas nas principais Regiões Metropolitanas (RM's) do país ${ }^{1}$. A pesquisa se concentrou na identificação e na caracterização de aspectos formais, sem arguir sobre aspectos qualitativos dos arranjos de gestão e governança metropolitanos.

Nesta esteira, o propósito do estudo foi buscar parâmetros objetivos que permitissem quantificar a fragilidade e a fragmentação institucional para gestão e governança das Regiões e analisar como produzir uma comparação dos arranjos e articulações entre elas. No que diz respeito à institucionalização de um sistema de gestão metropolitano, foi averiguada a existência dos seguintes elementos no âmbito dos arranjos institucionais: instâncias responsáveis pela gestão da RM; fundos para financiamento específico de ações na RM; conselhos consultivo e deliberativo; programas nos orçamentos estaduais e instrumentos de planejamento. Com o intuito de efetivar uma análise comparativa, foram desenhadas duas RM's hipotéticas, as quais contariam com grande adensamento institucional e forte articulação para gestão e governança metropolitanas, segundo os mesmos componentes e critérios utilizados na análise dos casos concretos. Para compor o quadro de referência dessas regiões hipotéticas, foram pensadas duas possibilidades: uma RM de "primeira geração", instituída na década de 1970, e outra mais recente, delimitada após a Constituição de 1988, na década de 2000; assim, o arranjo ideal em termos de arranjo institucional, teria:

instância de gestão exclusiva, mantida com a mesma estrutura desde a criação, identificada como uma secretaria estadual específica para a gestão da RM; instâncias setoriais exclusivas de gestão metropolitana, incluindo: agência; assembleia e ao menos cinco órgãos setoriais metropolitanos destinados à gestão das principais FPIC - Funções Públicas de Interesse Comuns-, ou seja, aquelas mais diretamente relacionadas ao

1 A saber: as Regiões metropolitanas de São Paulo, Belo Horizonte, Recife, Porto Alegre, Goiânia, Curitiba, Salvador, Rio de Janeiro, Fortaleza, Vitória, Ride Distrito Federal, Belém, São Luís, Vale do Rio Cuiabá e Manaus. 
desenvolvimento urbano metropolitano: transportes, saneamento (água, esgoto e drenagem), resíduos sólidos, habitação e uso do solo; fundos operantes e alimentados com recursos destinados tanto ao planejamento e à gestão metropolitanos quanto a uma carteira de investimentos estruturais em projetos e infraestrutura; conselhos deliberativo e consultivo, o primeiro com participação da sociedade civil, ambos atuando desde a criação da RM, com frequência mínima de reuniões registradas em ata (ao menos uma reunião nos últimos seis meses); programas específicos para a RM nos dois últimos orçamentos plurianuais estaduais - 2008-2011 e 2012-2015. Foram pensados ao menos sete programas: um para cada FPIC principal - transporte, saneamento, resíduos sólidos, habitação e uso do solo; além de dois para planejamento e gestão; planos metropolitanos, elaborados e vigentes na última década; e diversidade e quantidade significativa de articulações institucionais entre entes e atores para a governança, incluindo ao menos: quinze consórcios (dois para cada FPIC principal: transporte, saneamento, resíduos sólidos, habitação e uso do solo; mais um consórcio para cada uma das seguintes funções: saúde, educação, cultura e meio ambiente); doze tipos de articulação para gestão de FPIC (um para cada FPIC principal: transporte, saneamento, resíduos sólidos, habitação e uso do solo; dois para planejamento e gestão da RM; uma articulação para cada uma das seguintes funções: saúde, educação, cultura e meio ambiente); dez outros tipos, entre: comissões, comitês, conselhos, fóruns e associações de municípios. (COSTA; TSUKUMO, 2013, p.19,20)

A análise comparativa do estudo mostra que nenhuma das Regiões estudadas alcançaria o resultado de referência dos casos hipotéticos de alta densidade e coesão institucional. A pesquisa concluiu que

apenas $47 \%$ das RMs contam com instância exclusiva de gestão; apesar de a maioria $(80 \%)$ ter conselho deliberativo instituído legalmente; $73 \%$ possui fundo legalmente instituído, mas $60 \%$ destes fundos nunca foram alimentados; $80 \%$ possui conselho deliberativo instituído, mas apenas $33 \%$ prevê a participação da sociedade civil, e dois terços não tiveram reunião no último ano; e somente um terço das RMs possuem, ou estão elaborando, seus planos metropolitanos. (COSTA; TSUKUMO, 2013, p.24)

As principais regiões metropolitanas estudadas apresentam, portanto, um quadro de institucionalização frágil, embora houvesse casos em que ocorrera institucionalização de alguns dos elementos avaliados, isso não significou um sistema contínuo. Conforme a pesquisa, são dois dados que caracterizam claramente a fragilidade e fragmentação metropolitana, quais sejam o tempo de operação e o número de instâncias responsáveis pela gestão da região. O primeiro indicador mostra, na maioria dos casos, a prevalência de instituições com pouco tempo de existência, de um a dois anos, indicando rotatividade na estrutura de gestão formalmente designada pelos governos estaduais para planejamento e gestão da região. O segundo demonstra a fragilidade institucional dos arranjos institucionais, a maioria das regiões contou com três a seis instâncias de gestão (COSTA; TSUKUMO, 
A análise permitiu, portanto, que os pesquisadores criassem tipos de arranjos de gestão e governança das regiões. Em relação a um "sistema de gestão institucionalizado", estabeleceram-se três estágios: consolidado; em consolidação/ou de consolidação incipiente; e não consolidado. O grupo de regiões com sistema de gestão consolidado representou quarenta por cento dos casos (São Paulo, Belo Horizonte, Recife, Porto Alegre, Goiânia, Curitiba) sendo que cinco delas pertencem ao grupo de regiões criadas na década de 1970 (São Paulo, Belo Horizonte, Recife, Porto Alegre e Curitiba); mas sessenta por cento delas não se encontram ainda institucionalmente consolidadas (Salvador, Rio de Janeiro, Vitória, Ride e Belém) e mais de um quarto destas regiões, na verdade, possui sistemas de gestão não consolidados (Fortaleza, São Luís, Vale do Rio Cuiabá e Manaus) (COSTA; TSUKUMO, 2013).

Em relação à articulação de entes e atores para governança metropolitana, a classificação se deu em níveis forte, médio e fraco. As regiões de primeira geração - São Paulo e Belo Horizonte apresentaram articulação forte; Recife, Porto Alegre e Curitiba, articulação média - e a RM de Goiânia, articulação fraca. Este resultado indica que as regiões metropolitanas instituídas com critérios nacionais, na década de 1970, apresentam arranjos mais consolidados, bem como número e diversidade de articulações entre entes e atores para sua governança; sessenta por cento das regiões apresentam um grau fraco de articulações institucionais para a governança; apenas duas delas apresentam um grau forte e quatro delas, um grau médio, cumprindo destacar que todas estas seis regiões metropolitanas fazem parte do grupo daquelas criadas na década de 1970 (COSTA; TSUKUMO, 2013)

Outro grupo de regiões apresenta sistemas em consolidação ou de consolidação incipiente, mas com fraca articulação para governança. Ele é composto, em sua maioria, também por algumas importantes regiões de primeira geração (criadas em 1970) como Salvador, Rio de Janeiro e Belém; e por Vitória e a Região Integrada de Desenvolvimento Econômico do Distrito Federal (Ride/DF). O último grupo se caracteriza por um sistema de gestão ainda não consolidado, envolvendo regiões metropolitanas com média ou fraca articulação para governança. Neste grupo, encontram-se as regiões de Cuiabá, Manaus e São Luís, recentemente criadas e ainda com fragilidades institucionais e de articulação (COSTA; TSUKUMO, 2013)

A pesquisa concluiu que há grande diversidade de arranjos institucionais e articulações em diferentes estágios de formalização no âmbito das principais regiões metropolitanas do país e com predomínio de arranjos institucionais consolidados entre as 
regiões metropolitanas da década de 70. Entretanto, ainda assim, algumas das regiões mais antigas e a grande maioria das mais recentes apresentam um quadro institucional formal ainda não consolidado com predomínio de articulações institucionais fracas. Há, portanto, fragilidade e a fragmentação da gestão e da governança metropolitanas mesmo nas regiões mais antigas, da década de 1970, que comparativamente às outras regiões, apresentam resultados relativos melhores, porém ao comparar com o que seria o tipo ideal de região metropolitana, deixa muito a desejar (COSTA; TSUKUMO, 2013).

Observa-se, nesta pesquisa, que das quinze regiões estudadas, somente São Paulo e Belo Horizonte, conforme a tipologia criada, apresentam sistema de gestão consolidado e de articulação forte; porém, mesmo estas, estariam distantes do que o estudo considerou ideal; todas as outras regiões estão em níveis muito abaixo.

Nota-se que o estudo tratou das principais regiões metropolitanas do país e mesmo nestas, há clara deficiência e fragilidade do instrumento de regionalização.

$\mathrm{O}$ que pode ter gerado isso? A crise econômica dos anos oitenta e noventa, que atingiram gravemente as finanças dos Estados da Federação, pode ter contribuído para esse esvaziamento da gestão metropolitana; além disso, os recursos tributários dos Municípios e Estados são insuficientes para que estes sejam reais protagonistas dos investimentos de infraestrutura social e urbana tão necessários à região metropolitana. Há, então, forte dependência dos recursos e repasses da União, a qual se ausentou na discussão da região metropolitana, afinal ela não regulamenta e tampouco formula critérios para sua criação, mas é ela quem tem recursos para efetivar investimentos. Embora estes sejam desejáveis, quando ocorrem, alteraram significativamente o espaço, alterações com as quais os Estados e Municípios devem lidar em nível metropolitano. Tem-se um grande paradoxo, a União embora não seja protagonista legal na questão metropolitana, o é de fato, pois é ela quem tem os recursos necessários para a gestão da região; embora estes sejam necessários para garantir a imprescindível infraestrutura, eles modificarão o espaço e estas mudanças devem ser enfrentadas pelos Estados e Municípios figurantes de fato na questão metropolitana (COSTA; TSUKUMO, 2013)

O restante das regiões metropolitanas, não abordado no estudo, é até questionado se representa de fato um espaço metropolitano; por tal razão não foram analisados. Porém, o fato de as principais regiões, de maior capacidade estratégica e localizados em áreas de maior 
força política e financeira já estarem distantes do ideal, as outras provavelmente não estarão em melhor situação.

Por fim, a questão metropolitana é um campo de conflito por excelência, os atores políticos, agentes econômicos e a própria população podem se confrontar em torno de uma série de questões relacionadas ao uso e apropriação do território, porém conseguir solucionar estes conflitos significa avançar nas regulamentações desses pontos polêmicos e desordenados, envolveria delimitar o que cabe a cada ator, a cada agente ou ainda a cada esfera de governo e definir os mecanismos de articulação. A gestão metropolitana é a que seria responsável pela integração dessas dimensões, sendo, portanto, tão necessária avançar neste aspecto.

Tendo em vista a real situação das regiões metropolitanas no país e o objetivo ideal destas, passemos para a análise do recente Estatuto da Metrópole.

\section{O Estatuto da Metrópole}

No dia 12 de janeiro de 2015 foi sancionado o Estatuto da Metrópole, projeto de lei proposto em 2004, cuja discussão e sanção eram tão aguardadas por urbanistas e planejadores urbanos. Para ser sancionada, a Lei Federal 13.089/2015 ficou dez anos em tramitação e sofreu uma série de emendas e substitutivos para, ao fim, conseguir aprovação no Congresso Nacional.

Embora seja interessante analisar o percalço percorrido pelo Projeto de lei até aqui, este artigo irá se focar na análise, somente, dos destaques trazidos por este novo Estatuto.

Como o próprio artigo primeiro da lei enuncia:

estabelece diretrizes gerais para o planejamento, a gestão e a execução das funções públicas de interesse comum em regiões metropolitanas e em aglomerações urbanas instituídas pelos Estados, normas gerais sobre o plano de desenvolvimento urbano integrado e outros instrumentos de governança interfederativa, e critérios para o apoio da União a ações que envolvam governança interfederativa no campo do desenvolvimento urbano (...).

Neste momento, a lei já apresenta o objeto a ser regulamentado e a introdução de novos instrumentos de governança até então inexistentes na realidade jurídica e legislativa de muitas regiões metropolitanas.

A lei também traz conceitos importantes e essenciais para a melhor compreensão de denominações normalmente empregadas quando se aborda a questão metropolitana. Neste momento, define-se o que é aglomeração urbana, metrópole, região metropolitana e função 
pública de interesse comum; contudo, a novidade se apresenta com algumas definições e, com elas, certas obrigações por parte das regiões. É o caso da gestão plena (a condição de região ou aglomeração que possuem formalização e determinação mediante lei estadual), da estrutura de governança interfederativa e do plano de desenvolvimento integrado aprovado por lei estadual. As regiões com gestão plena serão aquelas em que existir uma real governança integrada e, eis o ponto novo, um plano de desenvolvimento.

Uma primeira observação que se pode fazer nesta parte inicial diz respeito aos tipos de morfologias que serão submetidos à Lei. Está claro que as disposições legais serão aplicadas às Regiões Metropolitanas (RM), Aglomerações Urbanas (AU) e Microrregiões. Embora seja essencial haver uma diretriz legal para estas morfologias urbanas, o Estatuto desconsiderou a rápida dinâmica urbana e o frequente surgimento de outras formações. Atualmente já se observa o surgimento de macrometrópoles e megalópoles, formações altamente adensadas e com redes de integração ainda mais complexas, por isso deve se pensar em sistemas de gestão e governança que acompanhem estas complexidades; ou seja, em um futuro não tão distante, toda a diretriz legal fundada para a gestão da Região Metropolitana pode se tornar insuficiente. Em São Paulo, por exemplo, já se enfrenta problemas de gestão intrametropolitana (MOURA; HOSHINO, 2015).

Apesar desta questão, a animação por, enfim, haver instrumentos normativos que orientem a instituição, gestão e governança de regiões metropolitanas é justificável. Este traz significativas inovações no campo da gestão e governança metropolitana, as quais, anteriormente, eram realizadas sem uma diretriz legal geral. $\mathrm{O}$ grande destaque apresentado, o principal e mais importante deles, é a gestão plena. Esta formaliza e delimita a Região Metropolitana, exige uma estrutura de governança interfederativa e um Plano de Desenvolvimento Urbano Integrado (PDUI) aprovado por lei estadual.

A primeira (governança interfederativa) diz respeito a uma instância executiva, uma instância colegiada deliberativa com representação da sociedade civil, uma organização pública com funções técnico-consultivas e um sistema integrado de alocação de recursos e de prestação de contas (art.8 da Lei em comento). É importante apontar que a gestão democrática estará presente na instância deliberativa, porém a lei não determina como se dará essa participação da sociedade civil; de qualquer maneira, seria essencial que tal participação não se desse em caráter pro forme como atualmente ocorre com as audiências públicas. Outra questão interessante a ser apontada é que não há um órgão para dirimir eventuais conflitos, os quais possivelmente serão levados ao Judiciário, trazendo um novo tipo de litígio que forçará 
este poder a se habituar e se profissionalizar com a questão urbanística e metropolitana, uma verdadeira novidade para o setor ${ }^{2}$ (MOURA; et al, 2015).

Já ao segundo, impõe-se o dever de se institui-lo por lei estadual e revisá-lo, pelo menos, a cada dez anos; suas diretrizes são estipuladas pelo artigo 12 da Lei. Um fator interessante desta inovação é que os Planos Diretores dos Municípios que fazem parte da RM ou AU devem ser compatibilizados com as diretrizes do PDUI, viabilizando assim um planejamento integrado em toda a região e cumprindo o que se espera de uma gestão integrada na região metropolitana.

Contudo, mais uma vez o Estatuto deixou de aproveitar uma excelente oportunidade, a de exigir essa mesma compatibilidade com outras Funções Públicas de Interesse Comum (FPIC), tais como planos de saneamento, de mobilidade urbana, de habitação de interesse social, de destinação do lixo urbano, etc. Embora os Planos Diretores sejam responsáveis por nortear todo o desenvolvimento urbano impondo diretrizes e metas a serem cumpridas e, neste sentido, impõe algumas articulações de políticas públicas que contemplem algumas das funções acima descritas, estas articulações não serão delimitadas de forma detalhada nesses Planos, mas sim em instrumentos distintos, onde se tratará de determinada função de forma mais minuciosa, delimitando a regulação necessária para que os objetivos sejam efetivados (MOURA; et al., 2015).

A necessidade de integrar todas essas funções em uma região metropolitana é essencial, tendo em vista a gravidade a que se chegou os problemas urbanos metropolitanos em função da densidade populacional e da falta de planejamento inteligente. A questão do lixo é exemplar, a produção de lixo na região metropolitana é elevada em razão da grande convivência e circulação de pessoas na área; a destinação do mesmo também se torna grave em função do pouco espaço territorial por ser tratar de espaços predominantemente urbanos. Ademais, tal destinação deve, ainda, respeitar determinações de cunho ambiental para não degradar a natureza e não colocar em risco a vida e saúde de pessoas residentes naquela área metropolitana.

A questão de moradia também merece ser comentada. Em função do elevado preço da terra nos núcleos metropolitanos, muitos dos cidadãos são obrigados a viver em periferias e

2 Embora já exista decisão do Supremo Tribunal Federal (STF) acerca da questão metropolitana - ADIn $\mathrm{n}^{\circ} .1842$ que reconheceu que a gestão dos serviços de saneamento básico deve ser compartilhada entre os Municípios e o Estado - identificando o caráter de cooperação inerente desta questão, ainda não se sabe como eventuais conflitos de governança interfederativa serão dirimidos pela Justiça. 
margens das cidades (expansão horizontal) ou viver em áreas irregulares ao redor dos núcleos. Essa situação atinge severamente a questão metropolitana, pois ao existir uma expansão horizontal/dispersão da cidade - urbanizando terras marginais para moradia - estimula-se a conurbação entre as cidades vizinhas, originando aglomerações urbanas. Em razão da distância dessas áreas dos núcleos metropolitanos, emerge o problema de transporte, devendose tratar das questões de mobilidade urbana. Justamente em função da distância, das dificuldades de mobilidade e do custo de uma terra regularizada, muitos são obrigados a viver em terrenos irregulares ao redor dos núcleos metropolitanos, vivendo em área não urbanizada com falta de serviços públicos, como saneamento básico, ou com o fornecimento de alguns serviços através de condutas ilegais (como os "gatos").

Nota-se, portanto, que são inúmeras as funções de interesse comum que precisam ser articuladas entre as cidades nas regiões metropolitanas, sendo interessante a adequação dos instrumentos legais referentes a tais funções ao PDUI.

Apesar desta ausência, exigir a sincronia entre os planos diretores e o plano integrado já é capaz de sintonizar, minimamente, as necessidades dos Municípios com as das Regiões Metropolitanas.

Entretanto, neste ponto, aponta-se mais uma questão importante. Conforme o Estatuto da Cidade, os planos diretores são exigidos para municípios com população acima de vinte mil habitantes e, também, para cidades integrantes de RM ou AU (artigo 41, Lei 10.257/01), tendo estes como prazo final para apresentar o plano outubro de 2006. De acordo com o MUNIC 2013 (IBGE, 2013) , no ano avaliado, metade dos municípios, especificamente 2.786, declararam ter Plano Diretor, 13,7\% (763) estavam elaborando-o e $36,2 \%$ (2.019) não o possuíam. Este percentual foi maior para os municípios com menos de vinte mil habitantes; porém considerando os municípios com mais de vinte mil habitantes, dos 1.718 que necessitavam elaborar o Plano Diretor, restaram $178(10,4 \%)$ que ainda não o haviam feito; destes, contudo, 108 (6,3\%) afirmaram que o Plano estava sendo elaborado. Embora tenha aumentado significativamente o número de municípios com Plano Diretores não se tem todos os municípios brasileiros, obrigados pela lei, com plano diretor; ora, o Estatuto da Cidade é de 2001 e o prazo final foi em 2006, ainda assim, não se conseguiu cumprir a determinação legal.

3 A sigla significa Pesquisa de Informações Básicas Municipais. 
Com isso em mente, a necessidade de se adequar o PDUI aos planos diretores ainda passaria pela necessidade de o município já ter elaborado seu plano diretor, o que, como visto acima, ainda não é uma realidade, podendo dificultar o avanço na gestão metropolitana caso o município sem plano diretor faça parte de uma RM ou AU.

Diferentemente de quando se determinou a obrigatoriedade do Plano Diretor, a não elaboração do PDUI no prazo de três anos da instituição da RM ou AU implicará em improbidade administrativa do governador ou do agente público; esta medida, talvez, foi implementada para evitar o que aconteceu com o plano diretor, pois passaram-se mais de dez anos desde a lei e alguns municípios obrigados ainda não elaboraram tal plano.

Por fim, a existência desse plano de desenvolvimento integrado configura condição essencial para o apoio da União às ações de desenvolvimento urbano integrado (Capítulo V), com relevo para as iniciativas dos Estados e dos Municípios voltadas à governança interfederativa (art. 14 Lei 13.089/2015) (MOURA; et al., 2015).

Um último destaque relacionado ao Estatuto diz respeito ao veto presidencial ao Fundo Nacional de Desenvolvimento Integrado cuja finalidade era captar recursos financeiros e apoiar ações de governança interfederativa em regiões metropolitanas e em consórcios públicos constituídos para atuar em FPIC’s no desenvolvimento urbano. As razões presidenciais ao veto foram de que "a criação de fundos cristaliza a vinculação a finalidades específicas, em detrimento da dinâmica intertemporal de prioridades políticas" e que os “(...) fundos não asseguram a eficiência, que deve pautar a gestão de recursos públicos” e, ainda que "(...) as programações relativas ao apoio da União ao desenvolvimento urbano integrado (...) podem ser executadas regularmente por meio de dotações orçamentárias consignadas no Orçamento Geral da União" (CAMPOS, 2015). Com este veto, novas formas de aquirir recursos financeiros para a gestão metropolitana foram impedidas; às RM`s, AU e Microrregiões, será permitido utilizar fundos públicos, operações urbanas consorciadas interfederativas, consórcios públicos, convênios de cooperação, contratos de gestão, parcerias público-privadas e apoio da União, neste último caso, desde que haja a gestão plena.

\section{O Estatuto e as Regiões Metropolitanas brasileiras}

Ao analisar os destaques trazidos pelo Estatuto e tendo exposto acima a situação das principais RM's do Brasil, sua consolidação e principais problemas é importante investigar se os instrumentos e determinações trazidos pela Lei abordam os principais pontos averiguados como problemáticos das Regiões Metropolitanas estudadas. 
As pesquisas concluíram que a maior parte das RM's apresentam fragilidade e fragmentação da gestão e da governança metropolitanas. Isso ocorre mesmo nas regiões mais antigas, da década de 1970, que comparativamente às outras regiões apresentam resultados relativos melhores; porém ao comparar com o que seria o tipo ideal de região metropolitana, também deixa muito a desejar.

Observa-se que as regiões instituídas sob a égide de uma governança central se apresentam relativamente em melhor situação, no que diz respeito à governança, do que as regiões mais recentes; porém, ainda aquém do modelo paradigma.

Como exposto acima, o arranjo ideal bem consolidado e com articulações fortes para a governança envolveria uma instância de gestão exclusiva (identificada como uma secretaria estadual específica para a gestão da RM) e instâncias setoriais exclusivas de gestão metropolitana para gerir as principais FPIC's como transporte, saneamento, habitação, resíduos sólidos e uso do solo. Envolve, ainda, fundos operantes e alimentados com recursos destinados tanto ao planejamento e à gestão metropolitanos quanto a uma carteira de investimentos estruturais em projetos e infraestrutura; conselhos deliberativo e consultivo, o primeiro com participação da sociedade civil com frequência mínima de reuniões registradas em ata (ao menos uma reunião nos últimos seis meses); programas específicos para a RM nos dois últimos orçamentos plurianuais estaduais; ao menos sete programas (um para cada FPIC principal) além de dois para planejamento e gestão; planos metropolitanos, elaborados e vigentes na última década; e diversidade e quantidade significativa de articulações institucionais entre entes e atores para a governança (COSTA; TSUKUMU, 2013).

Nota-se que, no geral, julgou-se como necessário uma instância exclusiva responsável por gerir somente a RM, um plano metropolitano, gestão exclusiva das principais FPIC's, fundos para prover os recursos, conselhos deliberativos e consultivos operantes, participação nos orçamentos plurianuais e cooperação entre todos os atores. O Estatuto prevê a criação do plano metropolitano, dos conselhos, compatibilização dos planos plurianuais, lei de diretrizes orçamentárias e orçamentos anuais dos entes envolvidos e sistema integrado de alocação de recursos e prestação de contas.

As pesquisas sobre o estado atual das regiões, ao final, constataram a fragilidade da gestão e a fraca cooperação dos entes envolvidos na região metropolitana. $\mathrm{O}$ fato de ter havido uma significativa mudança no tratamento metropolitano após a CF88 - a gestão deixou de ser centralizada - foi fundamental para a conformação atual da governança 
metropolitana; a falta de critérios para limitar a criação de RM's, a baixa cooperação entre os entes federativos e a pouca disponibilidade de recursos financeiros são alguns dos principais elementos a serem considerados quando se evidencia a fragilidade institucional e de governança das regiões.

O objetivo do Estatuto foi trazer uma diretriz central capaz de orientar o desenvolvimento metropolitano instigando e reforçando a necessária cooperação entre os entes federativos, além de determinar a instituição e fortalecimento de uma gestão plena das regiões. Conforme as pesquisas em comento, pode-se identificar como as principais dificuldades das RM's atuais a fragilidade institucional, a fraca articulação entre os entes e os parcos recursos financeiros para arcar com funções públicas de interesse comuns de tamanha complexidade.

Quanto ao primeiro, o Estatuto apresenta de forma bem estruturada o sistema de gestão plena, obrigando a elaboração de Plano de Desenvolvimento Integrado (inclusive quando prevê punições caso este não seja elaborado) e exigindo a adequação dos planos diretores a eles - o que corrobora com a edificação de um sistema realmente integrado -, além de vincular o apoio da União à existência desse sistema de gestão. $\mathrm{O}$ enfoque da lei, portanto, foi o de direcionar e fortalecer a governança metropolitana. Porém, um aspecto importante não foi concebido pelo Estatuto, qual seja a gestão exclusiva das principais FPIC's como transporte, saneamento básico, resíduos sólidos, moradias, dentre outros; como estas são altamente complexas e exigem profundos conhecimentos técnicos e montante de recursos para serem adequadamente implementadas, geri-las de forma exclusiva contribuiria com o fortalecimento da governança metropolitana, tornando-a operante e satisfatória.

Quanto ao segundo aspecto, a articulação entre os entes, ou seja, a cooperação entre eles, nota-se o esforço da lei em fomentá-la através da existência de uma governança integrada. A questão, porém, é verificar a vontade política dos entes federativos neste âmbito, afinal existirão investimentos a serem feitos para tratar de determinadas FPIC's e, por vezes, será necessário que o ente de maior capacidade financeira aplique maiores investimentos ou, ainda, o Município com esta característica deverá fazê-lo em detrimento daqueles com menores capacidades. Embora o serviço beneficie a todos igualmente, nem todos contribuirão com o mesmo montante de recursos. Isto pode causar certos conflitos políticos e mal estar. O formato de governança integrada trazido pelo Estatuto fomenta a necessidade de solidariedade e cooperação para se chegar a um resultado eficiente. Neste caso, por maiores que sejam os 
esforços legais, a articulação se fortalecerá à medida que houver maturidade política para lidar com o fenômeno metropolitano.

Por fim, quanto à alocação de recursos, tem-se um aspecto sensível. Uma das análises da Pesquisa constatou a necessidade de fundos para se prover recursos para as RM's (COSTA; TSUKUMO, 2013). O único fundo de grande capacidade previsto na lei foi vetado. A maior parte dos recursos advirá de alianças com a iniciativa privada; neste caso, deve-se ter uma regulação forte o suficiente para não haver cooptação do poder público aos interesses do poder privado e fiscalização eficiente para averiguar boa prestação do serviço; afinal, o interesse da iniciativa privada é maximizar seus lucros e, para tanto, investir em setores que lhes sejam rentáveis podendo ocorrer, então, marginalização de setores sociais importantes ao longo das parcerias.

A inexistência do fundo enfraquece o próprio Estatuto. Esta constatação decorre da análise da descentralização brasileira pós Constituição de 1988 e os desafios dos Estados e Municípios na federação.

À época da promulgação da Carta Magna e nos anos seguintes, o Brasil passou por crises financeira e fiscal que atingiram gravemente o setor público. As décadas foram marcadas por crises econômicas, financeiras, administrativas e política (inclusive com o impeachment do presidente Fernando Collor), por reajustes fiscais, plano real e políticas neoliberais. O momento histórico se mostra relevante quando se analisa como foram estipuladas as atribuições de competências para cada ente federativo. Esta descentralização ocorreu contemporaneamente ao processo de democratização em um momento de profunda crise econômica; houve, portanto, uma identificação entre a luta contra a ditadura com a luta pela descentralização. Dessa forma, na elaboração da Constituição de 1988 a União ficou "sem defensores" e a descentralização ocorreu de forma pouco articulada (AFFONSO, 1996). Essa descoordenação pode ser sentida quando se nota o aumento das transferências federais da União para os Estados e Municípios e respectiva descentralização fiscal em favor destes entes acompanhada da elevação de seus encargos. Estes dois entes passaram a assumir maiores responsabilidades nas prestações de serviços locais, como Educação, Saúde e Saneamento. A ampliação da capacidade financeira foi acompanhada do aumento significativo da despesa pública (AFFONSO, 1996).

Os Estados-membros, por exemplo, tiveram estipuladas competências remanescente (artigo 25, CF/88) e exclusiva de instituir regiões metropolitanas (artigo 25, §3º - além das 
competências comum e concorrente (artigos 23 e 24 respectivamente, CF/88). Em contraposição, os Municípios - elevados a ente federativo por esta Carta Magna - têm a responsabilidade de organizar e prestar serviços de interesse local; manter e prestar programas de Educação Infantil, de Ensino Fundamental e os serviços de atendimento à saúde; promover adequado ordenamento territorial mediante planejamento e controle do uso, do parcelamento e da ocupação do solo urbano e promover a proteção do patrimônio histórico-cultural local (artigo 30, CF88). Além destas, ainda existem as competências concorrentes, compartilhadas com Estados e União (artigo 23, CF88).

Embora em um primeiro momento pós Constituição (1989-1995), os Municípios recebessem um boom de recursos em razão de uma elevação de receitas originadas especialmente de transferências governamentais; em um segundo momento (1995-2002), quando tais transferências se estabilizaram, a União elevou os tributos não partilháveis com os demais entes e recuperou sua participação na arrecadação, fazendo com que a elevação das receitas municipais ficasse a cargo da arrecadação própria dos Municípios. Por fim, em terceira etapa (2003-2010) houve uma pequena elevação do valor das transferências governamentais, embora ainda houvesse fortalecimento institucional da União (SANTOS, 2012). A autonomia financeira municipal é posta em xeque.

Nota-se, então, que com a estabilização dos recursos municipais e a manutenção de suas obrigações de financiamento, os Municípios se viram em uma situação frágil. Suas receitas não comportam todos seus compromissos. Aliado a isso, a partir dos anos 90, em função também da necessidade de ajustes fiscais em função da crise econômica e financeira do país, o governo central adota modelo neoliberal de gestão e coloca o Município como principal promotor do desenvolvimento econômico local (SANTOS,2006). Dessa forma, tem- se a elevação do Município a ente federado, aumento de compromissos e responsabilidade municipais com políticas públicas e estabilização de recursos financeiros.

Tem-se, portanto, uma situação delicada. A descentralização federativa trazida pela Constituição distribuiu responsabilidades e recursos financeiros entre os entes, porém estes últimos foram acompanhados pela elevação de encargos e responsabilidades na prestação de serviços públicos. Ainda assim, é o Estado quem institui a região metropolitana cuja gestão dependerá de cooperação - politica e financeira - tanto daquele ente quanto dos Municípios envolvidos. Além desses entes precisarem arcar com suas responsabilidades na prestação de serviços públicos, devem, ainda, aprender a cooperar e arcar com serviços de nível metropolitano. 
Esta cooperação torna-se ainda mais difícil de se alcançar quando se observa que esta descentralização estimulou uma espécie de disputa entre entes e cidades. Esta concorrência é clara em relação à divisão de competências, por exemplo, em que Executivo federal, Legislativo federal e governos subnacionais disputam pelo poder de comando sobre gasto público; ou ainda no que diz respeito às receitas fiscais com disputas entre Estados e Municípios através da guerra fiscal (AFFONSO, 1996). Em um modelo de governança cada vez mais empreendedorista ${ }^{4}$, cidades concorrem entre si para atrair investimentos privados e Estados-membros se lançam em guerras de incentivos e benefícios fiscais para atrair indústrias para suas regiões. Temse um modelo que estimula a competição e uma ideologia metropolitana e o próprio Estatuto que incentiva a cooperação. Tudo isso com restrição financeira e limitação de recursos.

Dessa forma, o fundo seria uma forma de facilitar a concretização da gestão metropolitana, trazendo recursos para que esta se tornasse possível. Sem ele, tal gestão pode até ser viável, mas encontrará maiores dificuldades.

Obviamente, o Estatuto não foi concebido para ser a panaceia para os problemas metropolitanos brasileiros e ainda que o fosse, não conseguiria, pois a questão metropolitana é da ordem urbana e, por isso, é viva; transformações acontecerão cotidianamente trazendo problemas de maiores ou menores magnitudes que exigirão novas soluções políticas e administrativas. Ocorre que, embora tenha trazido a necessária gestão plena com a consequente preocupação com governança interfederativa, o Estatuto apresenta um formato de cooperação que dependerá de outros fatores que estão além da abordagem normativa.

\section{Conclusão}

Este estudo teve o objetivo de analisar o recém-sancionado Estatuto da Metrópole, uma inovação no discurso urbanístico de um fenômeno não tão recente e cada vez mais consolidado no país: a metropolização. Os problemas oriundos de uma metropolização não organizada são facilmente constatados, sendo visíveis desde a (i)mobilidade urbana até o descarte de resíduos sólidos. Entender o espaço metropolitano e geri-lo como tal viabiliza

$4 \mathrm{O}$ termo empreendedorismo urbano é utilizado por David Harvey. O autor demonstra as mudanças ocorridas a partir dos anos 70 em função das crises do petróleo, a falência do modelo fordista de produção e das crises administrativa, financeira e política que o Estado keynesiano, tão forte até os anos 60, sofreu. Estas crises estimularam a diminuição do tamanho do Estado e fomentaram um modelo de governança empreendedorista, em que o Estado é visto como uma empresa e o poder público se esforça para atrair capital privado como forma de angariar recursos. Com a adoção dessa governança, fenômenos como parcerias público-privadas se tornam cada vez mais comuns. Para um estudo aprofundado, recomendamos a leitura de "A produção capitalista do espaço" de David Harvey. 
melhor integração entre municípios conurbados e o próprio Estado-membro, permitindo que estes se desenvolvam de forma coordenada e sustentável.

Aliada à análise do Estatuto, foram expostos os principais resultados da pesquisa do IPEA (Governança Metropolitana no Brasil) sobre regiões metropolitanas, a qual identificou a situação institucional, de governança e de articulação das principais regiões metropolitanas no país. Foi elaborado um modelo ideal de governança metropolitana o qual foi comparado com as RM’s existentes e, assim, identificou-se quais os principais problemas e alguns dos motivos responsáveis pela fragilidade institucional e fraca articulação das regiões.

A partir desses resultados, este trabalho analisou as principais inovações do Estatuto e observou se estas seriam capazes de reestruturar as regiões metropolitanas e aproximá-las deste paradigma. Destacou-se, portanto, a importância da gestão plena trazida pela lei, que engloba a governança interfederativa e o Plano de Desenvolvimento Urbano Integrado (PDUI), essenciais para se instituir uma governança metropolitana e estimular a cooperação entre os entes; porém, criticou-se a inexistência de fundo de grande capacidade para arcar com os custos de administração e operacionalização das Funções Públicas de Interesse Comum (FPIC's;) além de inexistir gestão exclusiva das principais FPIC's.

Embora estas tenham sido as principais observações, mencionou-se ao longo do trabalho outras questões interessantes, como o fato de o Estatuto não tratar de fenômenos como a megalópole e macrometrópole, situações oriundas de desenvolvimento da questão metropolitana, ou ainda a não exigência de adequar a gestão das principais FPIC's - que normalmente se dá por instrumentos que não seja o plano diretor da cidade - ao PDUI, como foi feito para o Plano Diretor.

Por fim, concluiu-se, ainda, que uma das maiores dificuldades quanto à gestão metropolitana diz respeito à necessária cooperação entre os entes. Os instrumentos trazidos pelo Estatuto exigem que Estados e Municípios cooperem entre si, porém, o formato da descentralização brasileira e o modelo empreendedorista de governança instigam a competição entre aqueles entes. É uma situação delicada e paradoxal. A governança das regiões tal qual dispõe o Estatuto dependerá de fatores externos, principalmente políticos, para que seja concretizada.

Isso tudo não nega a importância do Estatuto, mas enfatiza os árduos caminhos a serem trilhados para que a governança metropolitana seja sólida, eficiente, bem articulada e capaz de fomentar o desenvolvimento sustentável das regiões metropolitanas do país. 


\section{Referências bibliográficas}

AFFONSO, Rui. Os Municípios e os desafios da federação. In: São Paulo em perspectiva, 10(3), 1996.

ALVES, Alaôr Caffé. Regiões Metropolitanas, Aglomerações Urbanas e Microrregiões: Novas Dimensões Constitucionais da Organização do Estado Brasileiro. Disponível em: <http://www.pge.sp.gov.br/centrodeestudos/revistaspge/revista/tes1.htm> . Acesso /em: 03/05/2015.

\section{BRASIL. Constituição da República Federativa do Brasil de 1988.}

BRASIL. Lei 13.089 de 12 de Janeiro de 2015. "Institui o Estatuto da Metrópole, altera a Lei $\mathrm{n}$ - 10.257 , de 10 de julho de 2001, e dá outras providências”. Diário Oficial da União, seção $1, n^{\circ} .8$, terça-feira, 13 de Janeiro de 2015.

BRASIL. Lei 12.257 de 10 de Julho de 2001. "Regulamenta os arts. 182 e 183 da Constituição Federal, estabelece diretrizes gerais da política urbana e dá outras providências”. Diário Oficial da União - Seção 1 - Eletrônico - 11/7/2001, Página 1 (Publicação Original).

BRIFFAULT, Richard. Localism and Regionalism. In: Public Law \& Legal Theory Working Paper Group; paper number one. Columbia Law School, 1999. Disponível em: $<$ http//papers.ssrn.com/paper.taf?abstract_id=198822>. Acesso em: 08/10/2014.

CAMPOS, Ana Cristina. Dilma sanciona o Estatuto da Metrópole. Agência Brasil, 13 de janeiro de 2015. Disponível em: < http://agenciabrasil.ebc.com.br/geral/noticia/201501/estatuto-da-metropole-e-sancionado > Acesso em: 03/05/2015.

COSTA, Marco Aurélio; TSUKUMO, Isadora Tami Lemos (Org.). 40 anos de Regiões Metropolitanas no Brasil. Volume 1. Série Rede Ipea. Projeto Governança Metropolitana no Brasil. Disponível em:

<http://www.ipea.gov.br/redeipea/images/pdfs/governanca metropolitana/livro_40_anos_de_r egioes_metropolitanas_v1_web.pdf>. Acesso em 03/05/2015.

HARVEY, David. A produção capitalista do espaço. São Paulo: Annablume, 2005.

INSTITUTO BRASILEIRO DE GEOGRAFIA E ESTATÍSTICAS - IBgE. Pesquisa de Informações Básicas Municipais 2013. Disponível em: <ftp://ftp.ibge.gov.br/Perfil_Municipios/2013/munic2013.pdf >. Acesso em: 03/05/2015. 
MOURA, Rosa; HOSHINO, Thiago de Azevedo Pinheiro. Estatuto da metrópole: enfim, aprovado! Mas o que oferece à metropolização brasileira? Disponível em: <http://www.observatoriodasmetropoles.net/download/estatuto_metropole_artigo_rosa.pdf $>$. Acesso em 03/05/2015.

SANTOS, Ângela Moulin Penalva. Planejamento urbano: para quê e para quem? In: Revista de Direito da Cidade. Rio de Janeiro/UERJ, n. 1, v. 1, 2006.

. Descentralização e autonomia municipal: uma análise das transformações institucionais no federalismo brasileiro. In: Geo UERJ - Ano 14, no. 23,v. 2, $2^{\circ}$ semestre de 2012 p. 825-852. Disponível em: <http://www.epublicacoes.uerj.br/index.php/geouerj> Acesso em: 06.04.2015. 